\title{
Rivaroxaban in Chronic Hemodialysis Patients: Clarification of an Editorial Error
}

\author{
Clapton Dias $^{\mathrm{a}}$ Kenneth Todd Moore ${ }^{\mathrm{a}} \quad$ Joe Murphy ${ }^{\mathrm{a}} \quad$ Jay Ariyawansa ${ }^{\mathrm{a}}$ William Smith $^{\mathrm{b}}$ \\ Roger M. Mills ${ }^{a}$ Matthew R. Weir ${ }^{c}$ \\ a Janssen Research \& Development, LLC, Raritan, N.J., ${ }^{\text {b } V o l u n t e e r ~ R e s e a r c h ~ G r o u p, ~ U n i v e r s i t y ~ o f ~ T e n n e s s e e ~ M e d i c a l ~}$ \\ Center, Knoxville, Tenn., and ' Division of Nephrology, Department of Medicine, University of Maryland School of \\ Medicine, Baltimore, Md., USA
}

The recently published Editorial by Muster and Alcorn [1] contains an inaccuracy related to the incidence of thrombosis reported in our manuscript entitled, 'Pharmacokinetics, Pharmacodynamics, and Safety of Single-Dose Rivaroxaban in Chronic Hemodialysis' [2]. Muster and Alcorn [1] state the following: 'During the study, no significant adverse events were reported except for 2 venous thromboses deemed unrelated to the rivaroxaban'. As noted in our publication [2], only 1 incidence of venous thrombosis, specifically an incidence of arteriovenous shunt thrombosis, was reported. The following text appears at the end of the 'Results' section of our manuscript: 'No bleeding events occurred during the study. Three subjects in
Group A experienced 4 adverse events, including 2 episodes of nausea, 1 of gingivitis and 1 of arteriovenous shunt thrombosis. None of the adverse events were deemed serious by the site investigator'. As noted in the Erratum [2], the number of subjects in Group A who experienced the 4 adverse events should have been written as 2 instead of 3 as given in the original publication.

\section{Disclosure Statement}

J.A. is a full-time employee of Janssen Research \& Development, LLC. C.D., K.T.M., J.M. and R.M.M. were full-time employees of Janssen Research \& Develop- ment, LLC, at the time of manuscript preparation. K.T.M. is a full-time employee of Janssen Scientific Affairs, LLC. W.S. has no conflicts of interest to disclose. M.R.W. served as a scientific advisor to Janssen.

\section{References}

1 Muster H, Alcorn H Jr: Rivaroxaban in chronic hemodialysis patients. Am J Nephrol 2016; 43:227-228.

2 Dias C, Moore KT, Murphy J, Ariyawansa J, Smith W, Mills RM, Weir MR: Pharmacokinetics, pharmacodynamics, and safety of single-dose rivaroxaban in chronic hemodialysis. Am J Nephrol 2016;43:229-236, erratum in Am J Nephrol 2016;43:170.

\section{KARGER}

E-Mail karger@karger.com www.karger.com/ajn
Kenneth Todd Moore, MS Janssen Scientific Affairs, LLC 1000 US Highway 202

Raritan, NJ 08869 (USA)

E-Mail tmoore17@its.jnj.com 